\title{
Finite Element Solution of Heat and Mass Transfer in MHD Flow of a Viscous Fluid past a Vertical Plate under Oscillatory Suction Velocity
}

\author{
J. Anand Rao ${ }^{1}$, R. Srinivasa Raju ${ }^{2 \dagger}$ and S. Sivaiah ${ }^{3}$ \\ ${ }^{I}$ Department of Mathematics, University College of Science, Osmania University, Hyderabad, 500007, \\ Andhra Pradesh, India. \\ ${ }^{2}$ Department of Basic Science and Humanities, Padmasri Dr. B. V. Raju Institute of Technology, Narsapur, \\ Medak (Dt), 502313, Andhra Pradesh, India. \\ ${ }^{3}$ Department of Mathematics, Gitam University, Hyderabad Campus, Hyderabad, 502329, Andhra Pradesh, India.
}

†Corresponding Author Email: srivass999@gmail.com

(Received September 11, 2009; accepted July 13, 2011)

\begin{abstract}
The study of hydromagnetic heat and mass transfer in MHD flow of an incompressible, electrically conducting, viscous fluid past an infinite vertical porous plate along with porous medium of time dependent permeability under oscillatory suction velocity normal to the plate has been made. It is considered that the influence of the uniform magnetic field acts normal to the flow and the permeability of the porous medium fluctuate with the time. The problem is solved, numerically by Galerkin finite element method for velocity, temperature, concentration field and the expressions for skin - friction, Nusselt number and Sherwood number are also obtained. The results obtained are discussed for Grashof number $(\mathrm{Gr}>0)$ corresponding to the cooling of the plate and $(\mathrm{Gr}<0)$ corresponding to the heating of the plate with the help of graphs and tables to observe the effects of various parameters.
\end{abstract}

Keywords: Heat and mass transfer, MHD flow, Vertical plate, Suction velocity, Viscous fluid, Galerkin finite element method.

\section{INTRODUCTION}

In industries and nature, many transport processes exist in which heat and mass transfer takes place simultaneously as a result of combined buoyancy effect of thermal diffusion and diffusion of chemical species. The phenomenon of heat and mass transfer is observed in buoyancy induced motions in the atmosphere, in bodies of water, quasi - solid bodies, such as earth and so on. Unsteady oscillatory free convective flows play an important role in chemical engineering; turbo machinery and aerospace technology such flows arise due to either unsteady motion of a boundary or boundary temperature. Besides, unsteadiness may also be due to oscillatory free stream velocity and temperature. In the past decades an intensive research effort has been devoted to problems on heat and mass transfer in view of their application to astrophysics, geo-physics and engineering. In addition, the phenomenon of heat and mass transfer is also encountered in chemical process industries such as polymer production and food processing. Many researchers have studied the problems on free convection and mass transfer flow of a viscous fluid through porous medium. In these studies, the permeability of the porous medium is assumed to be constant. However, a porous material containing the fluid is a non-homogeneous medium and the porosity of the medium may not necessarily be constant. Gebhart and Pera (1971) discussed the nature of vertical natural convection flows resulting from the combined buoyancy effects thermal and mass diffusion. Singh and Singh (1983) studied mass transfer effects on unsteady MHD free convective flow past an infinite vertical porous plate with variable suction. Raptis and Soundalgekar (1984) discussed the steady laminar free convection flow of an electrically conducting fluid along a porous hot vertical plate in the presence of heat source/sink.

Lai (1991) presented coupled heat mass transfers by mixed convection form a vertical plate in a saturated porous medium. Jha and Prasad (1992) discussed the effects of applied magnetic field on transient free convective flow in a vertical channel. Abdur Sattar (1994) intiated free convection and mass transfer flow through a porous medium past an infinite vertical porous plate with time dependent temperature and concentration. Singh (1994) showed the effect of mass transfer on free convection in MHD flow of a viscous fluid. Singh and Kumar (1995) studied an integral treatment for combined heat and mass transfer by natural convection in a porous medium. Soundalgekar et al. (1995) discussed coupled heat mass 
transfer by natural convection from vertical surface in porous medium. Singh et al. (1996) explained free convection heat and mass transfer along a vertical surface in a porous medium. Singh (1996) studied the mass transfer effects on the flow past a vertical porous plate. Srikanth et al. (1996) have analyzed the effect of mass transfer on unsteady free convection flow past infinite vertical porous plate. Singh et al. (1999) discussed the hydromagnetic free convective and mass transfer flow of a viscous stratified liquid. Acharya et al. (2000) have reported magnetic field effects on the free convection and mass transfer flow through porous medium with constant suction and constant heat flux.

Singh (2000) presented an oscillatory hydromagnetic couette flow in a rotating system. Kinyanjui et al. (2001) presented magnetohydrodynamic free convection heat and mass transfer of a heat generating fluid past an impulsively started infinite vertical porous plate with hall current and radiation absorption. Kumar et al. (2002) studied an unsteady oscillatory laminar free convection flow of an electrically conducting fluid through a porous medium along a porous hot vertical plate with time dependent suction in the presence of heat source/sink. Takhar et al. (2002) studied MHD flow over a moving plate in a rotating fluid with magnetic field, hall currents and free stream velocity. Singh et al. (2003) studied the effects of permeability variation and oscillatory suction velocity on free convection and mass transfer flow of a viscous fluid past an infinite vertical porous plate to a porous medium when the plate is subjected to a time dependent suction velocity normal to the plate in the presence of uniform transverse magnetic field.

The permeability of the porous medium is considered to be $K_{O}\left(t^{\prime}\right)=K_{O}^{\prime}\left(1+\varepsilon e^{i \eta^{\prime} t^{\prime}}\right)$ and the suction velocity is assumed to be $v\left(t^{\prime}\right)=-v_{0}\left(1+\varepsilon e^{i \eta^{\prime} t^{\prime}}\right)$ where $v_{\mathrm{o}}>0$ and $\varepsilon<<1$ is a positive constant. Ganesh and Pilani (2004) studied Finite Difference analysis of unsteady natural convection MHD flow past an inclined plate with variable surface heat and mass flux. Abdur Sattar and Abdul Maleque (2005) estimated the effects of variable properties and hall current on steady MHD laminar convective fluid flow due to a porous rotating disk. Samad et al. (2005) studied MHD boundary layer flow over a heated stretching sheet with variable Viscosity. Venkateshwarlu and Anand Rao (2005) have given the numerical solution of heat and mass transfer in MHD flow of a viscous fluid past a vertical plate under oscillatory suction velocity. Prasad et al. (2006) studied transient radiative hydromagnetic free convection flow past an impulsively started vertical plate with uniform heat and mass flux. Ogulu et al. (2007) studied the unsteady MHD free Convective flow of compressible fluid past a moving vertical plate in the presence of radiative heat transfer. Sharma et al. (2007) studied the hall effect on MHD mixed convective flow of a viscous incompressible fluid past a vertical porous plate immersed in porous medium with heat source/sink. Prasad et al. (2011) discussed finite difference analysis of radiative free convection flow past an impulsively started vertical plate with variable heat and mass flux. Suneetha et al. (2011) discussed
Radiation and Mass transfer effects on MHD free convective Dissipative fluid in the presence of heat source/sink.

Vasu et al. (2011) studied the radiation and mass transfer effects on transient free convection flow of a dissipative fluid past semi-infinite vertical plate with uniform heat and mass flux. In all these studies, the oscillatory suction velocity in presence of time dependent viscosity along with the influence of uniform magnetic field are not studied while such flows are encountered in various fields, such as, astrophysics, geophysics, engineering, aerodynamics, and soil sciences. In the present paper, the same investigation is obtained by using Galerkin finite element method, which is more economical from computation viewpoint.

\section{Mathematical Analysis}

An unsteady hydromagnetic flow of viscous, incompressible, electrically conducting fluid past an infinite vertical porous plate in a porous medium of time dependent permeability and suction velocity is considered as shown in Fig. 1.

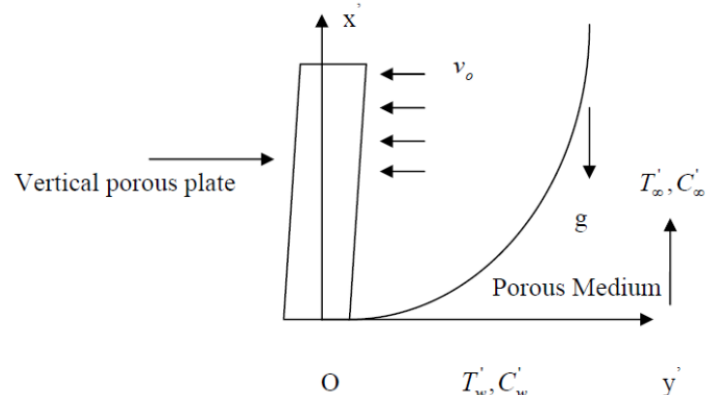

Fig. 1. Physical sketch and geometry of the problem

In Cartesian co - ordinate system, $x^{\prime}$ - axis is assumed to be along plate in the direction of the flow and $y^{\prime}$ axis normal to it. A uniform magnetic field is introduced normal to the direction of the flow. In the analysis, it is assumed that the magnetic Reynolds number is much less than unity so that the magnetic induced field, Further, all the fluid properties are assumed to be constant except that of the influence of the density variation of the temperature. Therefore, the basic flow in the medium is entirely due to buoyancy force caused by temperature difference between the wall and medium. Initially $t^{\prime} \leq 0$, the plate as well as fluid is assumed to be at the same temperature and the concentration of species is very low so that the Soret and Dofour effect are neglected. When $t^{\prime}>0$, the temperature of the plate is instantaneously raised (or lowered) to $T_{w}^{\prime}$ and the concentration of the species is raised (or lowered) to $C_{w}^{\prime}$.

Under the stated assumptions and taking the usual Boussinesq's approximation in to account, the governing equations for momentum, energy and concentration in dimensionless form are: 
Continuity Equation:

$\frac{\partial v^{\prime}}{\partial t^{\prime}}=0$

Momentum Equation:

$$
\begin{aligned}
& \frac{\partial u^{\prime}}{\partial t^{\prime}}+v^{\prime} \frac{\partial u^{\prime}}{\partial y^{\prime}}=g \beta\left(T^{\prime}-T_{\infty}^{\prime}\right)+g \beta^{*}\left(C^{\prime}-C_{\infty}^{\prime}\right) \\
& +v \frac{\partial^{2} u^{\prime}}{\partial y^{\prime 2}}-v \frac{u^{\prime}}{K_{O}{ }^{\prime}}-\frac{\sigma B_{0}^{2} u^{\prime}}{\rho}
\end{aligned}
$$

Energy Equation:

$$
\frac{\partial T^{\prime}}{\partial t^{\prime}}+v^{\prime} \frac{\partial T^{\prime}}{\partial y^{\prime}}=\frac{k}{\rho C_{p}} \frac{\partial^{2} T^{\prime}}{\partial y^{\prime 2}}
$$

Concentration Equation:

$$
\frac{\partial C^{\prime}}{\partial t^{\prime}}+v^{\prime} \frac{\partial C^{\prime}}{\partial y^{\prime}}=D \frac{\partial^{2} C^{\prime}}{\partial y^{\prime 2}}
$$

where $u^{\prime}$ is the velocity along the $x^{\prime}$ - axis, $v^{\prime}$ is the kinematic coefficient of viscosity, $g$ is the acceleration due to gravity, $\beta$ is the coefficient of volume expansion for the heat transfer, $\beta^{*}$ is the volumetric coefficient of expansion with species concentration, $T$ ' is the fluid temperature, $T_{\infty}^{\prime}$ is the fluid temperature at infinity, $C^{\prime}$ is the species concentration, $C_{\infty}^{\prime}$ is the species concentration at infinity, D is the chemical molecular diffusivity, $\varepsilon$ - porosity of the porous medium, $k_{e}$ Mean absorption co-efficient , $K_{O}^{\prime}$ is the constant permeability of the medium, $\mu$ is the coefficient of viscosity, $C_{p}$ is the specific heat at constant pressure, $\eta$ is the frequency of oscillation, $\rho$ is the density of the fluid, $k_{r}^{\prime}$ - the chemical reaction parameter and $\mathrm{t}$ is the time. The corresponding boundary conditions are

$$
\begin{aligned}
& t^{\prime} \leq 0: u^{\prime}=0, T^{\prime}=T_{\infty}^{\prime}, C^{\prime}=C_{\infty}^{\prime} \text { for all } y^{\prime} \\
& t^{\prime}>0:\left\{\begin{array}{l}
u^{\prime}=0, T^{\prime}=T_{w}^{\prime}+\varepsilon\left(T_{w}^{\prime}-T_{\infty}^{\prime}\right) e^{i \eta^{\prime} t^{\prime},} \\
C^{\prime}=C_{w}^{\prime}+\varepsilon\left(C_{w}^{\prime}-C_{\infty}^{\prime}\right) e^{i \eta^{\prime} t^{\prime}} \text { at } y^{\prime}=0 \\
u^{\prime} \rightarrow 0, T^{\prime} \rightarrow T_{\infty}^{\prime}, C^{\prime} \rightarrow C_{\infty}^{\prime} \text { as } y^{\prime} \rightarrow \infty
\end{array}\right\}
\end{aligned}
$$

From the continuity equation, it can be seen that $v^{\prime}$ is either a constant or a function of time. So assuming suction velocity to be oscillatory about a non - zero constant mean, one can write $v^{\prime}=-v_{0}\left(1+\varepsilon e^{i \eta^{\prime} t^{\prime}}\right)$ where $v_{0}$ is the mean suction velocity, $\eta$ is frequency of oscillation and $v_{0}>0, \varepsilon<<1$ is a positive constant. The negative sign indicates that the suction velocity is directed towards the plate. The permeability of the porous medium is considered to be $K_{O}\left(t^{\prime}\right)=K_{O}^{\prime}\left(1+\varepsilon e^{i \eta^{\prime} t^{\prime}}\right)$.
The non dimensionless quantities introduced in these equations are defined as:

$$
\begin{aligned}
& y=\frac{v_{O} y^{\prime}}{4 v} ; t=\frac{v_{O}^{2} t^{\prime}}{4 v} ; \\
& n=\frac{4 v \eta^{\prime}}{v_{O}^{2}} ; u=\frac{u^{\prime}}{v_{O}} ; \\
& T=\frac{T^{\prime}-T_{\infty}^{\prime}}{T_{w}^{\prime}-T_{\infty}^{\prime}} ; C=\frac{C^{\prime}-C_{\infty}^{\prime}}{C_{w}^{\prime}-C_{\infty}^{\prime}} ; \\
& K_{O}=\frac{K_{O}^{\prime} v_{O}^{2}}{v^{2}}
\end{aligned}
$$

(Permeability of the medium);

$G r=\frac{v g \beta^{*}\left(T_{w}^{\prime}-T_{\infty}^{\prime}\right)}{v_{O}^{3}}($ Grashof Number $)$

$S c=\frac{v}{D}($ Schimidt Number $)$;

$\operatorname{Pr}=\frac{\mu C_{p}}{K_{t}}(\operatorname{Pr}$ andtl Number $) ;$

$M=\frac{B_{o}}{v_{o}} \sqrt{\frac{\sigma v}{\rho}}($ Hartmann number $)$

$\left.\begin{array}{c}G m=\frac{\operatorname{vg} \beta\left(C_{w}^{\prime}-C_{\infty}^{\prime}\right)}{v_{o}^{3}} \\ (\text { Modified Grashof Number }) . ;\end{array}\right\}$

The governing equations for momentum, energy and concentration in dimensionless form are:

$$
\begin{aligned}
& \frac{1}{4} \frac{\partial u}{\partial t}-\left(1+\varepsilon e^{\text {int }}\right) \frac{\partial u}{\partial y}=(G r) T+(G m) C+ \\
& \frac{\partial^{2} u}{\partial y^{2}}-\frac{u}{K_{O}\left(1+\varepsilon e^{\text {int }}\right)}-M^{2} u \\
& \frac{1}{4} \frac{\partial T}{\partial t}-\left(1+\varepsilon e^{\text {int }}\right) \frac{\partial T}{\partial y}=\frac{1}{\operatorname{Pr}} \frac{\partial^{2} T}{\partial y^{2}} \\
& \frac{1}{4} \frac{\partial C}{\partial t}-\left(1+\varepsilon e^{\text {int }}\right) \frac{\partial C}{\partial y}=\frac{1}{S c} \frac{\partial^{2} C}{\partial y^{2}}
\end{aligned}
$$

The relevant boundary conditions in dimensionless form are

$\left.\begin{array}{l}u=0, T=1+\varepsilon e^{\mathrm{int}}, C=1+\varepsilon e^{\mathrm{int}} \text { at } y=0 \\ u \rightarrow 0, T \rightarrow 0, \quad C \rightarrow 0 \quad \text { as } y \rightarrow \infty\end{array}\right\}$

\section{Method Of Solution}

By applying Galerkin finite element method for Eq. (7) over the element (e), $\left(y_{j} \leq y \leq y_{k}\right)$ is: $\int_{j}^{y}\left\{N^{T}\left[\begin{array}{c}\frac{\partial^{2} u^{(e)}}{\partial y^{2}}-\frac{1}{4} \frac{\partial u^{(e)}}{\partial t}+ \\ A \frac{\partial u^{(e)}}{\partial y}-R u^{(e)}+P\end{array}\right]\right\} d y=0$ 
Where $\mathrm{A}=1+\varepsilon e^{\text {int }}, \mathrm{R}=\frac{1}{K_{O} A}+M^{2}$,

$\mathrm{P}=(G r) T+(G m) C$

Integrating the first term in Eq. (11) by parts one obtains

$N^{(e) T}\left\{\frac{\partial u^{(e)}}{\partial y}\right\}_{y_{j}}^{y_{k}}-y_{j} y_{j}\left\{N^{(e) T}\left(\begin{array}{c}\frac{\partial N^{(e) T}}{\partial y} \frac{\partial u^{(e)}}{\partial y}+ \\ \frac{1}{4} \frac{\partial u^{(e)}}{\partial t}- \\ A u^{(e)} \\ R u^{(e)}-P\end{array}\right)\right] d y=0$

Neglecting the first term in Eq. (12), one gets:

$\int_{j}^{y_{k}}\left\{\begin{array}{l}\frac{\partial N^{(e) T}}{\partial y} \frac{\partial u^{(e)}}{\partial y}+N \\ y_{j}^{(e) T} \\ \left(\frac{1}{4} \frac{\partial u^{(e)}}{\partial t}-A \frac{\partial u^{(e)}}{\partial y}+R u^{(e)}-P\right)\end{array}\right\} d y=0$

Let $u^{(e)}=N^{(e)} \varphi^{(e)}$ be the finite element approximation solution over the element $\left(y_{j} \leq y \leq y_{k}\right)$

where $N^{(e)}=\left[\begin{array}{ll}N_{j} & N_{k}\end{array}\right], \varphi^{(e)}=\left[\begin{array}{ll}u_{j} & u_{k}\end{array}\right]^{T}$ and $N_{j}=\frac{y_{k}-y}{y_{k}-y_{j}}, N_{k}=\frac{y-y_{j}}{y_{k}-y_{j}}$ are the basis functions.

One obtains:

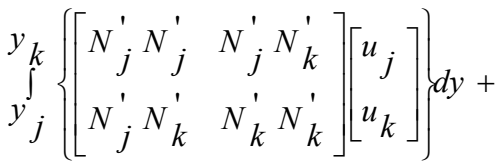

$$
\begin{aligned}
& \frac{1}{4} \int_{j}^{y_{k}}\left\{\left[\begin{array}{cc}
N_{j} N_{j} & N_{j} N_{k} \\
N_{j} N_{k} & N_{k} N_{k}
\end{array}\right]\left[\begin{array}{c}
\bullet \\
u_{j} \\
\bullet \\
u k
\end{array}\right]\right\} d y \\
& -\frac{A}{2 l^{(e)}} \int_{j}^{y_{k}}\left\{\left[\begin{array}{cc}
N_{j} N_{j}^{\prime} & N_{j} N_{k}^{\prime} \\
N_{j}^{\prime} N_{k} & N_{k}^{\prime} N_{k}
\end{array}\right]\left[\begin{array}{c}
u_{j} \\
u_{k}
\end{array}\right]\right\} d y \\
& +\frac{R}{6} \int_{j}^{y_{k}}\left\{\left[\begin{array}{cc}
N_{j} N_{j} & N_{j} N_{k} \\
N_{j} N_{k} & N_{k} N_{k}
\end{array}\right]\left[\begin{array}{c}
u_{j} \\
u_{k}
\end{array}\right]\right\} d y \\
& =P \int_{j}^{y}\left[\begin{array}{c}
N_{j} \\
N_{k}
\end{array}\right] d y
\end{aligned}
$$

Simplifying we get

$$
\begin{aligned}
& \frac{1}{l^{(e)^{2}}}\left[\begin{array}{rr}
1 & -1 \\
-1 & 1
\end{array}\right]\left[\begin{array}{l}
u_{j} \\
u_{k}
\end{array}\right]+\frac{1}{24}\left[\begin{array}{ll}
2 & 1 \\
1 & 2
\end{array}\right]\left[\begin{array}{l}
u_{j} \\
\bullet \\
u_{k}
\end{array}\right] \\
& -\frac{A}{2 l^{(e)}}\left[\begin{array}{ll}
-1 & 1 \\
-1 & 1
\end{array}\right]\left[\begin{array}{l}
u_{j} \\
u_{k}
\end{array}\right]+\frac{R}{6}\left[\begin{array}{ll}
2 & 1 \\
1 & 2
\end{array}\right]\left[\begin{array}{l}
u_{j} \\
u_{k}
\end{array}\right] \\
& =\frac{P}{2}\left[\begin{array}{l}
1 \\
1
\end{array}\right]
\end{aligned}
$$

Where prime and dot denotes differentiation w.r.to ' $y$ ' and time ' $t$ ' respectively. Assembling the element equations for two consecutive elements $\left(y_{i-1} \leq y \leq y_{i}\right)$ and $\left(y_{i} \leq y \leq y_{i+1}\right)$ following is obtained:

$$
\begin{aligned}
& \frac{1}{l^{(e)^{2}}}\left[\begin{array}{rrr}
1 & -1 & 0 \\
-1 & 2 & -1 \\
0 & -1 & 1
\end{array}\right]\left[\begin{array}{l}
u_{i-1} \\
u_{i} \\
u_{i+1}
\end{array}\right] \\
& +\frac{1}{24}\left[\begin{array}{ccc}
2 & 1 & 0 \\
1 & 4 & 1 \\
0 & 1 & 2
\end{array}\right]\left[\begin{array}{l}
\bullet \\
u i-1 \\
\bullet \\
\bullet i \\
u i+1
\end{array}\right]
\end{aligned}
$$$$
-\frac{A}{2 l^{(e)}}\left[\begin{array}{rrr}
-1 & 1 & 0 \\
-1 & 0 & 1 \\
0 & -1 & 1
\end{array}\right]\left[\begin{array}{l}
u_{i-1} \\
u_{i} \\
u_{i+1}
\end{array}\right]
$$$$
+\frac{R}{6}\left[\begin{array}{lll}
2 & 1 & 0 \\
1 & 4 & 1 \\
0 & 1 & 2
\end{array}\right]\left[\begin{array}{l}
u_{i-1} \\
u_{i} \\
u_{i+1}
\end{array}\right]
$$

$$
=\frac{P}{2}\left[\begin{array}{l}
1 \\
2 \\
1
\end{array}\right]
$$

Now put row corresponding to the node 'i' to zero, from Eq. (13) the difference schemes with $l^{(e)}=h$ is:

$$
\begin{aligned}
& \frac{1}{h^{2}}\left[-u_{i-1}+2 u_{i}-u_{i+1}\right]+\frac{1}{24}\left[\dot{u}_{i-1}+4 \dot{u} i+\dot{u} i+1\right] \\
& -\frac{A}{2 h}\left[-u_{i-1}+u_{i+1}\right]+\frac{R}{6}\left[u_{i-1}+4 u_{i}+u_{i+1}\right]=P
\end{aligned}
$$

Applying the trapezoidal rule, following system of equations in Crank-Nicholson method are obtained:

$$
\begin{aligned}
& A_{1} u_{i-1}^{n+1}+A_{2} u_{i}^{n+1}+A_{3} u_{i+1}^{n+1}= \\
& A_{4} u_{i-1}^{n}+A_{5} u_{i}^{n}+A_{6} u_{i+1}^{n}+12 P h k
\end{aligned}
$$

Now from Eqs. (7) and (8), following equations are obtained: 


$$
\begin{aligned}
& B_{1} T_{i-1}^{n+1}+B_{2} T_{i}^{n+1}+B_{3} T_{i+1}^{n+1}= \\
& B_{4} T_{i-1}^{n}+B_{5} T_{i}^{n}+B_{6} T_{i+1}^{n} \\
& C_{1} C_{i-1}^{n+1}+C_{2} C_{i}^{n+1}+C_{3} C_{i+1}^{n+1}= \\
& C_{4} C_{i-1}^{n}+C_{5} C_{i}^{n}+C_{6} C_{i+1}^{n}
\end{aligned}
$$

where

$\mathrm{A}_{1}=\mathrm{h}+2 \mathrm{Rk}-12 \mathrm{rh}+6 \mathrm{Ak}$

$\mathrm{A}_{2}=4 \mathrm{~h}+24 \mathrm{rh}+8 \mathrm{Rkh}$;

$\mathrm{A}_{3}=\mathrm{h}+2 \mathrm{Rk}-12 \mathrm{rh}-6 \mathrm{Ak}$

$\mathrm{A}_{4}=\mathrm{h}-2 \mathrm{Rk}+12 \mathrm{rh}-6 \mathrm{Ak}$;

$\mathrm{A}_{5}=4 \mathrm{~h}-24 \mathrm{rh}-8 \mathrm{Rkh}$

$\mathrm{A}_{6}=\mathrm{h}-2 \mathrm{Rk}+12 \mathrm{rh}+6 \mathrm{Ak}$;

$P=24 h(G r) k T_{i}^{j}+24 h(G m) k C_{i}^{j}$;

$\mathrm{B}_{1}=\mathrm{h}(\operatorname{Pr})+6 \mathrm{Ak}(\mathrm{Pr})-12 \mathrm{rh}$;

$\mathrm{B}_{2}=4 \mathrm{~h}(\operatorname{Pr})+24 \mathrm{rh}$

$\mathrm{B}_{3}=\mathrm{h}(\operatorname{Pr})-6 \mathrm{Ak}(\operatorname{Pr})-12 \mathrm{rh}$;

$\mathrm{B}_{4}=\mathrm{h}(\mathrm{Pr})-6 \mathrm{Ak}(\operatorname{Pr})+12 \mathrm{rh}$;

$\mathrm{B}_{5}=4 \mathrm{~h}(\mathrm{Pr})-24 \mathrm{rh}$;

$\mathrm{B}_{6}=\mathrm{h}(\operatorname{Pr})+6 \mathrm{Ak}(\operatorname{Pr})+12 \mathrm{rh}$

$\mathrm{C}_{1}=\mathrm{h}(\mathrm{Sc})+6 \mathrm{Ak}(\mathrm{Sc})-12 \mathrm{rh}$

$\mathrm{C}_{2}=4 \mathrm{~h}(\mathrm{Sc})+24 \mathrm{rh}$

$\mathrm{C}_{3}=\mathrm{h}(\mathrm{Sc})-6 \mathrm{Ak}(\mathrm{Sc})-12 \mathrm{rh}$;

$\mathrm{C}_{4}=\mathrm{h}(\mathrm{Sc})-6 \mathrm{Ak}(\mathrm{Sc})+12 \mathrm{rh}$

$\mathrm{C}_{5}=4 \mathrm{~h}(\mathrm{Sc})-24 \mathrm{rh}$

$\mathrm{C}_{6}=\mathrm{h}(\mathrm{Sc})+6 \mathrm{Ak}(\mathrm{Sc})+12 \mathrm{rh}$;

Here $\mathrm{r}=\frac{k}{h^{2}}$ and $\mathrm{h}, \mathrm{k}$ are mesh sizes along $\mathrm{y}-$ direction and time-direction respectively. Index ' $i$ ' refers to space and ' $\mathrm{j}$ ' refers to the time. In the Eqs. (15), (16) and (17), taking $\mathrm{i}=1(1) \mathrm{n}$ and using boundary conditions (10), then the following system of equations are obtained:

$$
A_{i} X_{i}=B_{i} \quad i=1(1) 3
$$

Where $A_{i}^{\prime}$ s are matrices of order $\mathrm{n}$ and $X_{i}, B_{i}^{\prime}$ s are column matrices having $\mathrm{n}$-components. The solutions of above system of equations are obtained by using Thomas algorithm for velocity, temperature and concentration. Also, numerical solutions for these equations are obtained by $\mathrm{C}$ - programme. In order to prove the convergence and stability of Galerkin finite element method, the same $\mathrm{C}$ - programme was run with smaller values of $\mathrm{h}$ and $\mathrm{k}$ and no significant change was observed in the values of $\mathrm{u}, \mathrm{T}$ and $\mathrm{C}$. Hence the Galerkin finite element method is stable and convergent.

\section{Skin-Friction, Rate of Heat and Mass Transfer}

Skin - Friction coefficient $(\tau)$ at the plate is $\tau=\left(\frac{\partial u}{\partial y}\right)_{y=0}$

Heat transfer coefficient $\left(\mathrm{N}_{\mathrm{u}}\right)$ at the plate is

$$
N_{u}=-\left(\frac{\partial T}{\partial y}\right)_{y=0}
$$

Mass transfer coefficient $\left(\mathrm{S}_{\mathrm{b}}\right)$ at the plate is

$$
S_{b}=-\left(\frac{\partial C}{\partial y}\right)_{y=0}
$$

\section{RESUltS AND DISCUSSION}

Some numerical calculations have been carried out for the non-dimensional velocity $(\mathrm{u})$, temperature $(\mathrm{T})$, concentration (C), skin - friction coefficient $(\tau)$ and heat and mass transfer coefficients in terms of Nusselt number $\left(\mathrm{N}_{\mathrm{u}}\right)$ and Sherwood number $\left(\mathrm{S}_{\mathrm{b}}\right)$ respectively. The effects of material parameters such as Prandtl number (Pr), Schmidt number (Sc), Hartmann number $(\mathrm{M})$, permeability parameter $\left(\mathrm{K}_{\mathrm{o}}\right)$, Grashof number $(\mathrm{Gr})$ and modified Grashof number $(\mathrm{Gm})$ have been observed. The numerical calculations of these results are presented graphically in Figs. 2 to 15.

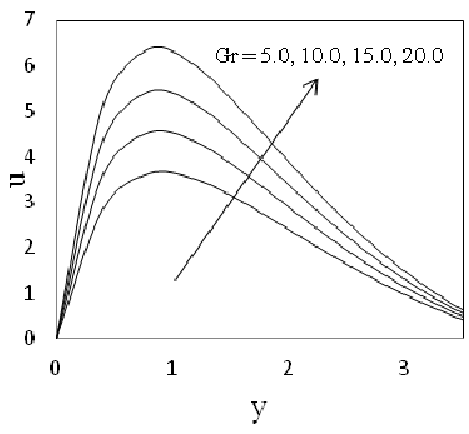

Fig. 2. Effect of Grashof number 'Gr' on velocity field ' $u$ ' for cooling of the plate when $\mathrm{Gm}=10.0, \mathrm{M}=0.5$, $\mathrm{Sc}=0.22, \operatorname{Pr}=0.71, \mathrm{~K}_{\mathrm{o}}=10.0, \varepsilon=0.005$ and $\mathrm{nt}=\pi / 2$.

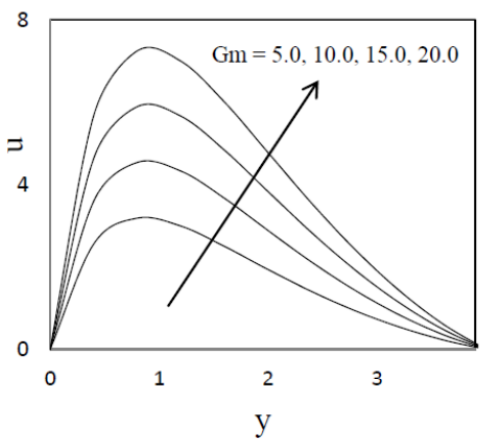

Fig. 3. Effect of modified Grashof number 'Gm' on velocity field ' $u$ ' for cooling of the plate when $\mathrm{Gr}=10.0, \mathrm{M}=0.5, \mathrm{Sc}=0.22, \operatorname{Pr}=0.71, \mathrm{~K}_{\mathrm{o}}=10.0, \varepsilon=$ 0.005 and $n t=\pi / 2$.

During the course of numerical calculations of the velocity, temperature and concentration, the values of the Prandtl number are chosen for air $(\operatorname{Pr}=0.71)$, electrolytic solution $(\operatorname{Pr}=1.0)$, water $(\operatorname{Pr}=7.0)$ and water at $4^{\circ} \mathrm{C}(\mathrm{Pr}=11.40)$. To focus out attention on numerical values of the results obtained in the study the values of Sc are chosen for the gases representing diffusing chemical species of most common interest in air namely Hydrogen $(\mathrm{Sc}=0.22)$, Water - vapour $(\mathrm{Sc}=$ $0.60)$, Oxygen $(\mathrm{Sc}=0.66)$, Ammonia $(\mathrm{Sc}=0.78)$, Methanol $(\mathrm{Sc}=1.00)$ and Propyl-benzene $(\mathrm{Sc}=2.62)$ at $20^{\circ} \mathrm{C}$ and one atmospheric pressure. 


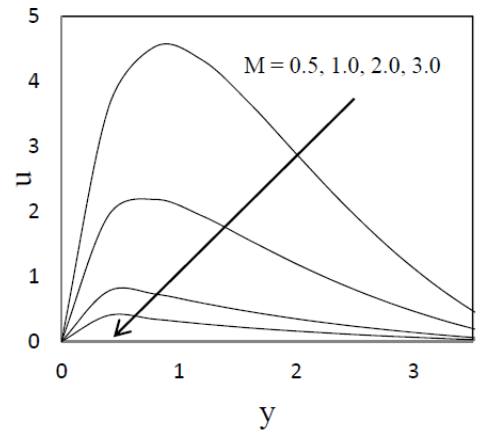

Fig. 4. Effect of Magnetic number ' $M$ ' on velocity field ' $u$ ' for cooling of the plate when $\mathrm{Gr}=10.0, \mathrm{Gm}=10.0$, $\operatorname{Pr}=0.71, \mathrm{Sc}=0.22, \mathrm{~K}_{\mathrm{o}}=10.0, \varepsilon=0.005$ and $\mathrm{nt}=\pi / 2$.

For the physical significance, only the real part of complex quantity is invoked for the numerical discussion in the problem and at $\mathrm{t}=1.0$, stable values for velocity, temperature and concentration fields are obtained. To examine the effect of parameters related to the problem on the velocity field and skin-friction numerical computations are carried out at $(\mathrm{Pr}=0.71)$ which corresponds to air at $25^{\circ} \mathrm{C}$ and one atmospheric pressure. The values of Grashof number $\mathrm{Gr}$ and modified Grashof number $\mathrm{Gm}$ are taken to be positive and negative as they respectively represent symmetric cooling of the plate when $\mathrm{Gr}>0$ and symmetric heating of the plate when $\mathrm{Gr}<0$. Since the flow is continuous flow which is tends to infinity. For finding solution of this problem we have placed infinite vertical plate in a finite length in the flow and hence we solved the entire problem in a finite boundary. However, in the graph yvalues vary from 0 to 4 , velocity, temperature and concentration tends to zero as y tends to 4 . This is true for any value of $\mathrm{y}$, thus we have considered finite length.

The temperature and the species concentration are coupled to the velocity via Grashof number $\mathrm{Gr}$ and modified Grashof number $\mathrm{Gm}$ as seen in Eq. (7). Figures 2-13 display the effects of material parameters such as $\mathrm{Gr}, \mathrm{Gm}, \mathrm{M}, \mathrm{Sc}, \mathrm{Pr}$ and $\mathrm{K}_{\mathrm{o}}$ on the velocity field for both externally cooling ( $\mathrm{Gr}>0)$ and heating $(\mathrm{Gr}<$ 0 ) of the plate. It is observed that an increase in the Grashof number or modified Grashof number leads to increase in the velocity field in both the presence of cooling and heating of the plate. For various values of Grashof number and modified Grashof number, the velocity profiles are plotted in Figs. 2 and 3. The Grashof number Gr signifies the relative effect of the thermal buoyancy force to the viscous hydrodynamic force in the boundary layer. As expected, it is observed that there is a rise in the velocity due to the enhancement of thermal buoyancy force. Here, the positive values of Gr correspond to cooling of the plate. Also, as Gr increases, the peak values of the velocity increases rapidly near the porous plate and then decays smoothly to the free stream velocity. The modified Grashof number $\mathrm{Gm}$ defines the ratio of the species buoyancy force to the viscous hydrodynamic force. As expected, the fluid velocity increases and the peak value is more distinctive due to increase in the species buoyancy force. The velocity distribution attains a distinctive maximum value in the vicinity of the plate and then decreases properly to approach the free stream value. It is noticed that the velocity increases with increasing values of the Solutal Grashof number.

The effect of Hartmann number $M$ is shown in the Fig. 4 in case of cooling of the plate. It is observed that the velocity of the fluid decreases with the increase of Hartmann number values. As expected, the velocity decreases with an increase in the Hartmann number. It is because that the application of transverse magnetic field will result in a resistive type force (Lorentz force) similar to drag force which tends to resist the fluid flow and thus reducing its velocity. Also, the boundary layer thickness decreases with an increase in the Hartmann number. We also see that velocity profiles decrease with the increase of magnetic effect indicating that magnetic field tends to retard the motion of the fluid. Magnetic field may control the flow characteristics.

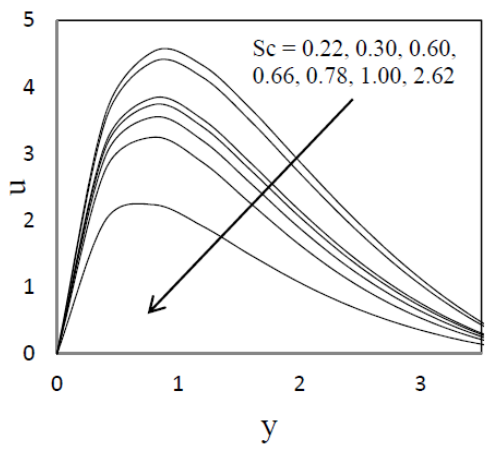

Fig. 5. Effect of Schmidt number 'Sc' on velocity field ' $u$ ' for cooling of the plate when $\mathrm{Gr}=10.0, \mathrm{Gm}=10.0$, $\operatorname{Pr}=0.71, \mathrm{M}=0.5, \mathrm{~K}_{\mathrm{o}}=10.0, \varepsilon=0.005$ and $\mathrm{nt}=\pi / 2$.

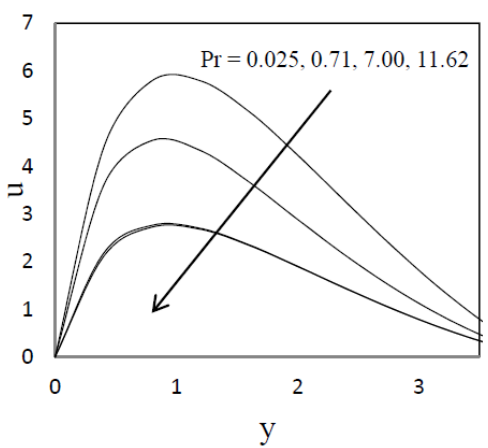

Fig. 6. Effect of Prandtl number 'Pr' on velocity field 'u' for cooling of the plate when $\mathrm{Gr}=10.0, \mathrm{Gm}=10.0$, $\mathrm{M}=0.5, \mathrm{Sc}=0.22, \mathrm{~K}_{\mathrm{o}}=10.0, \varepsilon=0.005$ and $\mathrm{nt}=\pi / 2$.

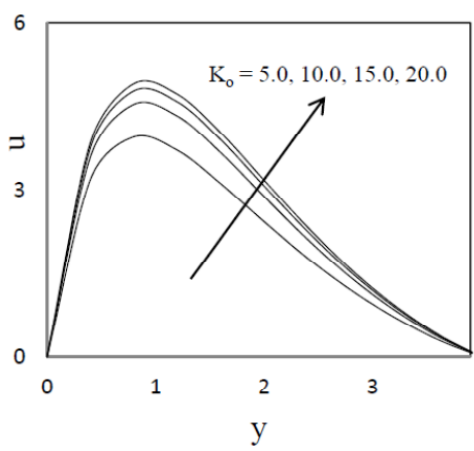

Fig. 7. Effect of Permeability parameter ' $K_{o}$ ' on velocity field ' $\mathrm{u}$ ' for cooling of the plate when $\mathrm{Gr}=10.0, \mathrm{Gm}=$ $10.0, \mathrm{M}=0.5, \mathrm{Sc}=0.22, \operatorname{Pr}=0.71, \varepsilon=0.005$ and $\mathrm{nt}=\pi / 2$. 
From Figs. 5 and 6 it is observed that an increase in $\mathrm{Sc}$ or Pr decreases the velocity field. A comparison of velocity distribution curves due to cooling of the plate show that in the vicinity of the plate the velocity falls very rapidly and thereafter steadily indicating that the curves rise gradually after attaining minimum value near the plate. Figure 7 shows the effect of the permeability of the porous medium parameter $\mathrm{K}_{\mathrm{o}}$ on the velocity distribution. As shown, the velocity is increasing with the increasing dimensionless porous medium parameter. The effect of the dimensionless porous medium $\mathrm{K}_{\mathrm{o}}$ becomes smaller as $\mathrm{K}_{\mathrm{o}}$ increase. Physically, this result can be achieved when the holes of the porous medium may be neglected.

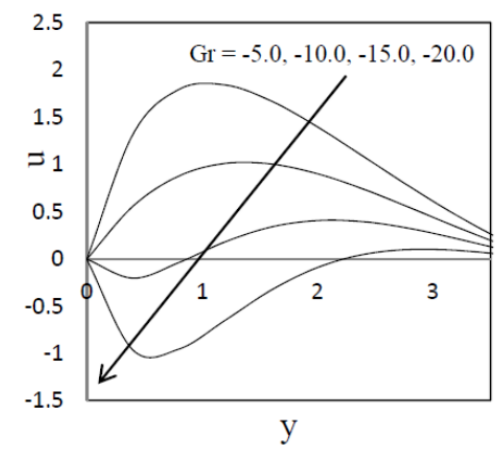

Fig. 8. Effect of Grashof number 'Gr' on velocity field ' $\mathrm{u}$ ' for heating of the plate when $\mathrm{Gm}=10.0, \mathrm{M}=0.5$, $\mathrm{Sc}=0.22, \operatorname{Pr}=0.71, \mathrm{~K}_{\mathrm{o}}=10.0, \varepsilon=0.005$ and $\mathrm{nt}=\pi / 2$.

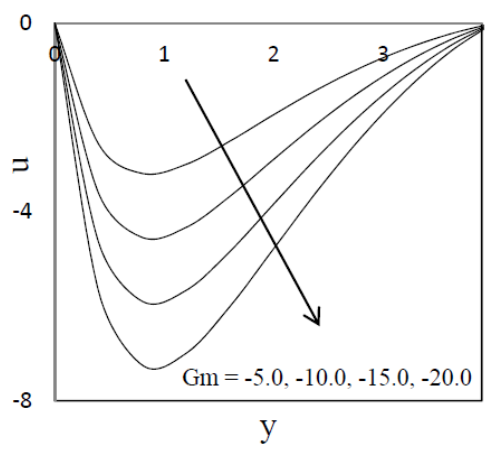

Fig. 9. Effect of modified Grashof number 'Gm' on velocity field ' $u$ ' for heating of the plate when $\mathrm{Gr}=-10.0, \mathrm{M}=0.5, \mathrm{Sc}=0.22, \mathrm{Pr}=0.71, \mathrm{~K}_{\mathrm{o}}=10.0$, $\varepsilon=0.005$ and $n t=\pi / 2$.

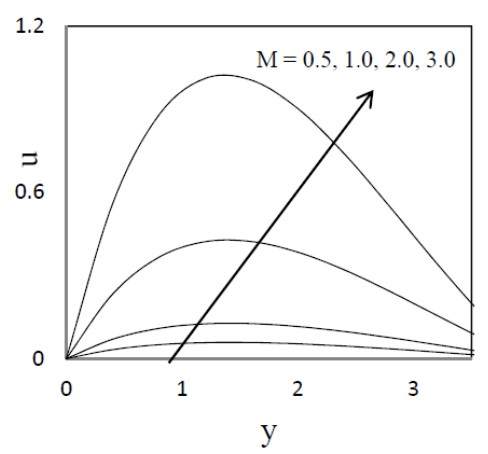

Fig. 10. Effect of Magnetic number ' $\mathrm{M}$ ' on velocity field ' $\mathrm{u}$ ' for heating of the plate when $\mathrm{Gr}=-10.0, \mathrm{Gm}=10.0$, $\operatorname{Pr}=0.71, \mathrm{Sc}=0.22, \mathrm{~K}_{\mathrm{o}}=10.0, \varepsilon=0.005$ and $\mathrm{nt}=\pi / 2$.
In the Figs. $8-13$, on velocity field mentioned above, compare to the case of cooling of the plate opposite effects are observed in the case of heating of the plate.

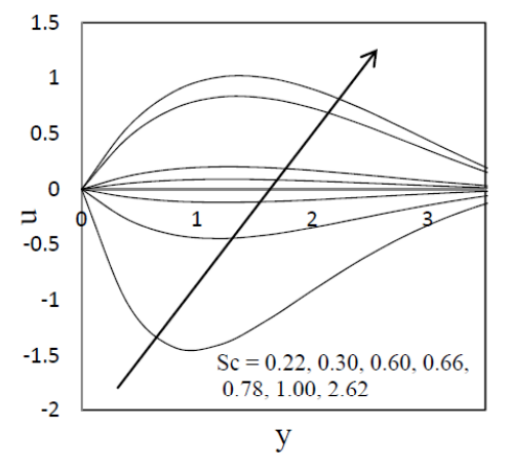

Fig. 11. Effect of Schmidt number 'Sc' on velocity field ' $u$ ' for heating of the plate when $\mathrm{Gr}=-10.0, \mathrm{Gm}=10.0$, $\operatorname{Pr}=0.71, \mathrm{M}=0.5, \mathrm{~K}_{\mathrm{o}}=10.0, \varepsilon=0.005$ and $\mathrm{nt}=\pi / 2$.

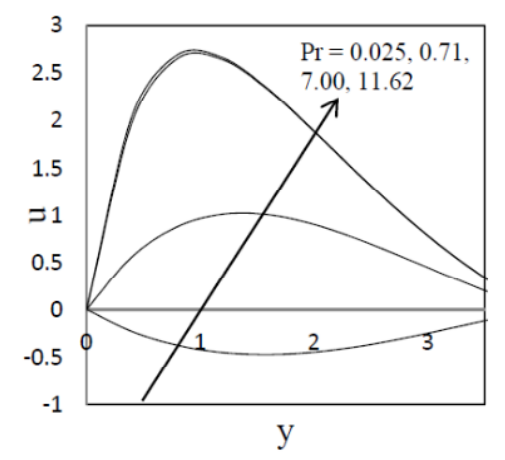

Fig. 12. Effect of Prandtl number 'Pr' on velocity field ' $u$ ' for heating of the plate when $\mathrm{Gr}=-10.0, \mathrm{Gm}=10.0$, $\mathrm{M}=0.5, \mathrm{Sc}=0.22, \mathrm{~K}_{\mathrm{o}}=10.0, \varepsilon=0.005$ and $\mathrm{nt}=\pi / 2$.

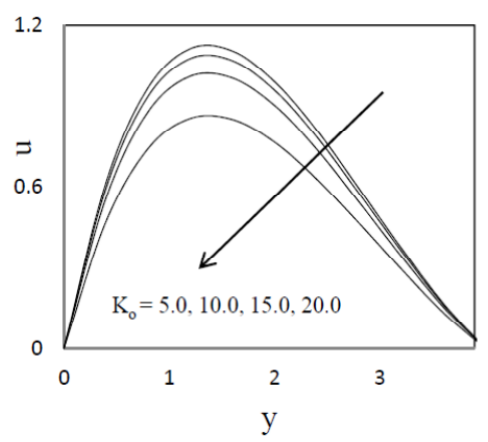

Fig. 13. Effect of Permeability parameter ' $\mathrm{K}_{\mathrm{o}}$ ' on velocity field ' $u$ ' for heating of the plate when $\mathrm{Gr}=$ 10.0, $\mathrm{Gm}=10.0, \mathrm{M}=0.5, \mathrm{Sc}=0.22, \operatorname{Pr}=0.71, \varepsilon=$ 0.005 and $n t=\pi / 2$.

An increase in Prandtl number decreases the Temperature field (Fig. 14). Also, Temperature field falls more rapidly for Water in comparison to Air and the Temperature field curve is exactly linear for Mercury, which is more sensible towards change in Temperature. From this observation it is concluded that Mercury is most effective for maintaining Temperature differences can be used efficiently in the laboratory. Air can replace Mercury, the effectiveness of maintaining the Temperature changes are much less than Mercury. If Temperatures are maintained, Air can be better and cheap replacement for industrial purposes. 
J. Anand Rao et al. / JAFM, Vol. 5, No. 3, pp. 1-10, 2012.

Table 1 Skin - Friction coefficient of $(\tau)$ for cooling of the plate.

\begin{tabular}{ccccccc}
\hline $\mathrm{Gr}$ & $\mathrm{Gm}$ & $\mathrm{M}$ & $\mathrm{Sc}$ & $\mathrm{Pr}$ & $\mathrm{K}_{\mathrm{o}}$ & $\tau$ \\
\hline 10.0 & 4.0 & 0.5 & 0.22 & 0.71 & 10.0 & 09.3769 \\
20.0 & 4.0 & 0.5 & 0.22 & 0.71 & 10.0 & 15.3029 \\
10.0 & 8.0 & 0.5 & 0.22 & 0.71 & 10.0 & 12.8276 \\
10.0 & 4.0 & 0.5 & 0.66 & 0.71 & 10.0 & 08.3830 \\
10.0 & 4.0 & 1.0 & 0.22 & 0.71 & 10.0 & 05.4383 \\
10.0 & 4.0 & 0.5 & 0.22 & 0.71 & 20.0 & 10.0271 \\
10.0 & 4.0 & 0.5 & 0.22 & 7.00 & 10.0 & 04.2190 \\
\hline
\end{tabular}

Table 2 Skin - Friction coefficient of $(\tau)$ for heating of the plate.

\begin{tabular}{ccccccc}
\hline $\mathrm{Gr}$ & $\mathrm{Gm}$ & $\mathrm{M}$ & $\mathrm{Sc}$ & $\mathrm{Pr}$ & $\mathrm{K}_{\mathrm{o}}$ & $\tau$ \\
\hline & & & & & & \\
-10.0 & 4.0 & 0.5 & 0.22 & 0.71 & 10.0 & -2.4753 \\
-20.0 & 4.0 & 0.5 & 0.22 & 0.71 & 10.0 & -8.4013 \\
-10.0 & 8.0 & 0.5 & 0.22 & 0.71 & 10.0 & 0.9755 \\
-10.0 & 4.0 & 0.5 & 0.66 & 0.71 & 10.0 & -3.4691 \\
-10.0 & 4.0 & 1.0 & 0.22 & 0.71 & 10.0 & -1.7868 \\
-10.0 & 4.0 & 0.5 & 0.22 & 0.71 & 20.0 & -2.5398 \\
-10.0 & 4.0 & 0.5 & 0.22 & 7.00 & 10.0 & 2.6826 \\
\hline
\end{tabular}

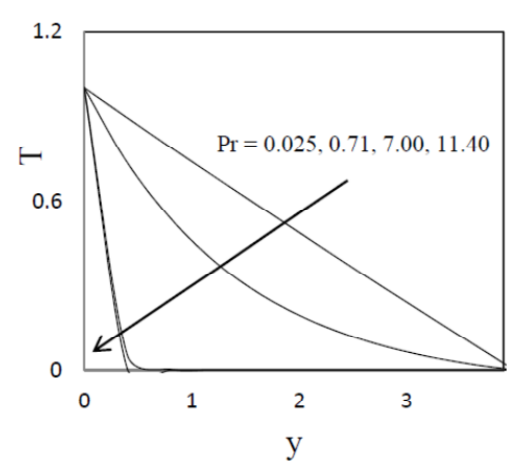

Fig. 14. Effect of Prandtl number 'Pr' on temperature field ' $\mathrm{T}$ ' when $\mathrm{Gr}=10.0, \mathrm{Gm}=10.0, \mathrm{M}=0.5, \mathrm{Sc}=0.22$, $\mathrm{K}_{\mathrm{o}}=10.0, \varepsilon=0.005$ and $\mathrm{nt}=\pi / 2$.

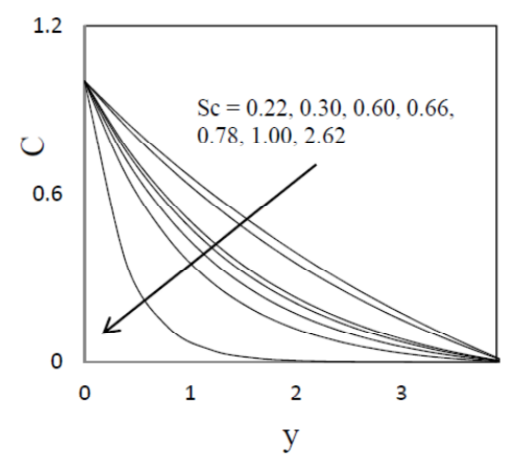

Fig. 15. Effect of Schmidt number 'Sc' on concentration field ' $\mathrm{C}$ ' when $\mathrm{Gr}=10.0, \mathrm{Gm}=10.0, \mathrm{M}=0.5, \mathrm{Sc}=0.22$,

$$
\mathrm{K}_{\mathrm{o}}=10.0, \varepsilon=0.005 \text { and } \mathrm{nt}=\pi / 2 \text {. }
$$

From Fig. 15, shows that an increase in Schmidt number decreases the concentration field. Also Concentration field falls slowly and steadily for Hydrogen and Helium but falls very rapidly for Oxygen and Ammonia in comparison to Water vapour. Thus
Water vapour can be used for maintaining normal Concentration field and Hydrogen can be used for maintaining effective Concentration field. In order to ascertain the accuracy of the numerical results, the present results are compared with the previous results of Venkateshwarlu and Anand Rao (2005) for $\mathrm{Gr}=$ $10.0, \mathrm{Gm}=10.0, \mathrm{M}=0.5, \mathrm{Sc}=0.22, \mathrm{Pr}=0.71, \mathrm{~K}_{\mathrm{o}}=$ $10.0, \varepsilon=0.005$ and $n t=\pi / 2$ in Fig. 16. They are found to be in an excellent agreement.

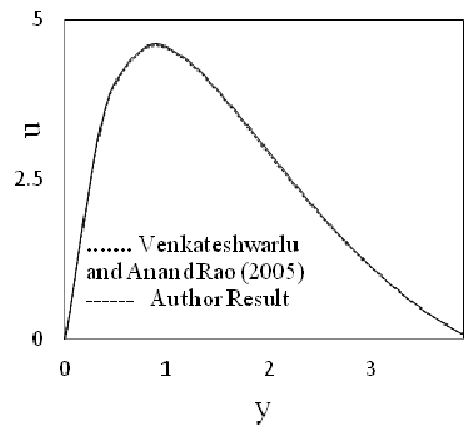

Figure 16. Effect of Permeability parameter ' $\mathrm{K}_{\mathrm{o}}$ ' on velocity field ' $u$ ' for cooling of the plate when $\mathrm{Gr}=10.0, \mathrm{Gm}=10.0, \mathrm{M}=0.5, \mathrm{Sc}=0.22, \mathrm{Pr}=0.71$, $\varepsilon=0.005$ and $n t=\pi / 2$.

Table 1 represents the numerical values of skin-friction coefficient $(\tau)$ for variations in $\mathrm{Gr}, \mathrm{Gm}, \mathrm{M}, \mathrm{Sc}, \mathrm{Pr}$, and $\mathrm{K}_{\mathrm{o}}$ respectively, corresponding to cooling of the plate. An increase in $\mathrm{Gr}$ or $\mathrm{Gm}$ or $\mathrm{K}_{\mathrm{o}}$ leads to an increase in the value of skin - friction coefficient while in increase in $\mathrm{M}$ or $\mathrm{Sc}$ or Pr leads to a decrease in the value of skin - friction coefficient.

Table 2 represents the numerical values of skin-friction coefficient $(\tau)$ for variations in $\mathrm{Gr}, \mathrm{Gm}, \mathrm{M}, \mathrm{Sc}, \mathrm{Pr}$, and $\mathrm{K}_{\mathrm{o}}$ respectively, corresponding to heating of the plate. An increase in $\mathrm{Gr}$ or $\mathrm{Gm}$ or Pr leads to an increase in 
the value of skin -friction coefficient while in increase in $\mathrm{M}$ or Sc or $\mathrm{K}_{\mathrm{o}}$ leads to a decrease in the value of skin - friction coefficient.

Table 3 Heat transfer coefficient in terms of Nusselt number.

\begin{tabular}{cc}
\hline $\operatorname{Pr}$ & $\mathrm{N}_{\mathrm{u}}$ \\
\hline 00.025 & 0.1239 \\
00.710 & 0.6868 \\
07.000 & 5.1852 \\
11.400 & 7.2611 \\
\hline
\end{tabular}

Table 4 Mass transfer coefficient in terms of Sherwood number.

\begin{tabular}{cc}
\hline $\mathrm{Sc}$ & $\mathrm{S}_{\mathrm{b}}$ \\
\hline 0.22 & 0.2525 \\
0.30 & 0.3168 \\
0.60 & 0.5852 \\
0.66 & 0.6406 \\
0.78 & 0.7514 \\
1.00 & 0.9525 \\
2.62 & 2.3165 \\
\hline
\end{tabular}

Table 3 represents the numerical values of heat transfer coefficient $\left(\mathrm{N}_{\mathrm{u}}\right)$ for different values of Prandtl number Pr. An increase in Pr leads to an increase in heat transfer coefficient. Also the value of $\mathrm{N}_{\mathrm{u}}$ is least for Mercury and highest for Water at $4^{\circ} \mathrm{C}$.

Table 4 represents the numerical values of mass transfer coefficient $\left(\mathrm{S}_{\mathrm{b}}\right)$ for different values of Schmidt number Sc. An increase in Sc leads to an increase in mass transfer coefficient. Also, the value of $\mathrm{S}_{\mathrm{b}}$ is least for Hydrogen and highest for Propyl benzene.

\section{Conclusion}

The problem "Finite element solution of heat and mass transfer in MHD flow of a viscous fluid past a vertical plate under oscillatory suction velocity" is studied. The dimensionless equations are solved by using Galerkin finite element method.

The effects of velocity, temperature and concentration for different parameters like Gr, Gm, M. Sc, Pr and $\mathrm{K}_{\mathrm{o}}$ are studied. The study concludes the following results:

1) The velocity decreases with the increasing of Hartmann number $\mathrm{M}$.

2) The velocity decreases with the increase of Prandtl number Pr and Schmidt number Sc for cooling of the plate $(\mathrm{Gr}>0)$ and the velocity increases with the increase of Prandtl number Pr and Schmidt number Sc for heating of the plate $(\mathrm{Gr}<0)$.

3) The velocity increases with the increase of Permeability parameter $\mathrm{K}_{\mathrm{o}}$ for cooling of the plate $(\mathrm{Gr}>0)$ and the velocity decreases with the increase of Permeability parameter $\mathrm{K}_{\mathrm{o}}$ for heating of the plate $(\mathrm{Gr}<0)$.

4) The velocity increases with the increasing of Grashof number Gr and Modified Grashof number Gm.

5) The temperature and Concentration decreases with increasing of Prandtl number $\mathrm{Pr}$ and Schmidt number Sc respectively.

6) In order to ascertain the accuracy of the numerical results, the present results are compared with the previous results of Venkateshwarlu and Anand Rao (2005) for $\mathrm{Gr}=10.0, \mathrm{Gm}=10.0, \mathrm{M}=0.5$, $\mathrm{Sc}=0.22, \operatorname{Pr}=0.71, \mathrm{~K}_{\mathrm{o}}=10.0, \varepsilon=0.005$ and $\mathrm{nt}=$ $\pi / 2$ in Fig. 16. They are found to be in an excellent agreement.

\section{REFERENCES}

Abdur Sattar and M.D. Kh. Abdul Maleque (2005). The effects of variable properties and hall current on steady MHD laminar convective fluid flow due to a porous rotating disk, Int. journal of heat and mass transfer 48, 4460 - 4466.

Abdusattar, M.D. (1994). Free convection and mass transfer flow through a porous medium past an infinite vertical porous plate with time dependent temperature and concentration. Ind journal of pure Application Math 25, 259 - 266.

Acharya, M., G.C. Dash and L.P. Singh (2000). Magnetic field effects on the free convection and mass transfer flow through porous medium with constant suction and constant heat flux. Ind Journal of Pure Application Math 31, 1 - 18.

Ganesh, P. and G. Pilani (2004). Finite difference analysis of unsteady natural convection MHD flow past an inclined plate with variable surface heat and mass flux. Int. Journal of Heat and Mass Transfer 47, 4449 - 4457.

Gebhart, B. and L. Pera (1971). The nature of vertical natural convection flows resulting from the combined buoyancy effects thermal and mass diffusion. International Journal of Heat Mass Transfer 14, 2025 - 2050.

Jain, M.K. (1984). Numerical solutions of differential equations. $2^{\text {nd }}$ edition, Wiley Eastern Limited, New Delhi.

Jha, B.K. and R. Prasad (1992). Effects of applied magnetic field on transient free convective flow in a vertical channel. Journal of Math Phy. Science $26,1-8$.

Kinyanjui, M., J.K. Kwanza and S.M. Uppal (2001). Magnetohydrodynamic free convection heat and mass transfer of a heat generating fluid past an impulsively started infinite vertical porous plate with Hall current and 
radiation absorption. Energy Conservation and Management 42, 917 - 931 .

Kumar, A., B. Chand and Kaushik (2002). On unsteady oscillatory laminar free convection flow of an electrically conducting fluid through porous medium along a porous hot vertical plate with time dependent suction in the presence of heat source/sink. Journal of Acad Math. 24, 339-354.

Lai, F.C. (1991). Coupled heat mass transfers by mixed convection form a vertical plate in a saturated porous medium. International Comm. Heat Mass Transfer 18, 93 - 106.

Ogulu, A., A.R.C. Amakiri and I.U. Mbeledogu (2007). Unsteady MHD free convective flow of a compressible fluid past a moving vertical plate in the presence of radiative heat transfer. Int. Journal of Heat and Mass Transfer 50, 1668 - 1674.

Prasad, V.R., N. Bhaskar Reddy and R. Muthucumaraswamy (2006). Transient radiative hydromagnetic free convection flow past an impulsively started vertical plate with uniform heat and mass flux. Theoretical Applied Mechanics 33(1), $31-63$.

Prasad, V.R., N. Bhaskar Reddy and R. Muthucumaraswamy (2011). Finite difference analysis of radiative free convection flow past an impulsively started vertical plate with variable heat and mass flux. Journal of Applied Fluid Mechanics 4(1), 59 - 68.

Raptis, A.A. and V.M. Soundalgekar (1984). Steady laminar free convection flow of an electrically conducting fluid along a porous hot vertical plate in the presence of heat source/sink. ZAMM 64, $127-130$.

Samad, Sk.A., G.C. Layek and S. Mukhopadhyaya (2005). MHD boundary layer flow over a heated stretching sheet with variable viscosity. Int. Journal of Heat and Mass Transfer 48, 4460 4466.

Sharma, B.K., A.K. Jha and R.C. Chaudhary (2007). Hall Effect on MHD Mixed Convective Flow of a Viscous Incompressible Fluid Past a Vertical Porous Plate Immersed in Porous Medium with Heat Source/Sink. Rom. Journal Phys 52(5), 487 - 503.

Singh, A.K., A.K. Singh and N.P. Singh (2003). Heat and mass transfer in MHD flow of a viscous fluid past a vertical plate under oscillatory suction velocity. Ind Journal of Pure Application Math 34, 429-442.

Singh, K.D., (2000). An oscillatory hydromagnetic Couette flow in a rotating system. ZAMM 80, PP. $429-432$.
Singh, N.P., A.K. Singh and M.K. Yadav (1999). Hydromagnetic free convective and mass transfer flow of a viscous stratified liquid. Journal of Energy Heat Mass Transfer 21, 111 - 115.

Singh, N.P. and R. Kumar (1995). An integral treatment for combined heat and mass transfer by natural convection in a porous medium. Acta Ciencia Indica 21(M), $451-463$.

Singh, N.P., A.K. Singh and R. Kumar (1996). Free convection heat and mass transfer along a vertical surface in a porous medium. Ind Journal of Theo Phys 44, 255-262.

Singh, N.P. (1996). Mass transfer effects on the flow past a vertical porous plate. Proceedings of Math Soc. 12, $109-114$.

Singh, N.P. (1994). Effect of mass transfer on free convection in MHD flow of a viscous fluid. Proceedings of Math Soc. 10, 59 - 62 .

Singh, A.K. and J. Singh (1983). Mass transfer effects on unsteady MHD free convective flow past an infinite vertical porous plate with variable suction. Astrophy. Space Science 91, 57 - 61.

Soundalgekar, V.M., S.N. Ray and U.N. Das (1995). Coupled heat mass transfer by natural convection from vertical surface in porous medium. Proceedings of Math Soc. 11, 95 - 98.

Srikanth, S., S. Venkata Ramana and S. Rama Krishna (1996). The effect of mass transfer on unsteady free convection flow past infinite vertical porous plate. Acta Ciencia Indica 22(M), $267-275$.

Suneetha, S., N. Bhaskar Reddy and V. Ramachandra Prasad (2011). Radiation and Mass transfer effects on MHD free convective Dissipative fluid in the presence of heat source/sink. Journal of Applied Fluid Mechanics 4(1), 107 - 113.

Takhar, H.S., A.J. Chamkha and G. Nath (2002). MHD flow over a moving plate in a rotating fluid with magnetic field, Hall currents and free stream velocity. Int. J. Engng Sci. 40(13), 1511 - 1527.

Vasu, B., V. Ramachandra Prasad and N. Bhaskar Reddy (2011). Radiation and mass transfer effects on transient free convection flow of a dissipative fluid past semi-infinite vertical plate with uniform heat and mass flux. Journal of Applied Fluid Mechanics 4(1), 15 - 26 .

Venkateshwarlu, K. and J. Anand Rao (2005). Numerical solution of heat and mass transfer in MHD flow of a viscous fluid past a vertical plate under oscillatory suction velocity.IE (I) Journal $M C, 85$. 